\title{
Effect of Polyethylene Glycol Microspheres Adsorbed with Melatonin on Oxidative Stress and Viscosity of Cervical Mucus Samples Infected with Human Papillomavirus
}

\author{
Aron Carlos de Melo Cotrim ${ }^{1(\mathbb{D})}$, Eduardo Luzia França ${ }^{2 *}{ }^{*}$, Adenilda Cristina Honório França ${ }^{2}(\mathbb{D})$, \\ Jordana Santos Martins ${ }^{2}$ (D), Katleyn Polizeli Galvão Silva ${ }^{2}{ }^{(D)}$,Yehya Chakib Ghalfi ${ }^{3}$ (D), Izabela \\ Trindade Machado $^{3}$ (D), Inês Aparecida Tozetti ${ }^{1}$ (iD \\ 1 Institute of Biosciences / Federal University of South Mato Grosso- Campo Grande - MS, Brazil \\ 2 Institute of Biological and Health Science - Federal University of Mato Grosso - Barra do Garças - MT, Brazil \\ 3 Prevenlab Laboratory - Barra do Garças - MT, Brazil \\ * Correspondence: dr.eduardo.franca@gmail.com;
}

Scopus Author ID 13605890500 Received: 27.04.2020; Revised: 19.05.2020; Accepted: 21.05.2020; Published: 27.05.2020

\begin{abstract}
The interfaces of hormones and endogenous molecules associated with nanostructured materials is one of the ways to evaluate the therapeutic potential. Melatonin is a neurohormone that is related to oxidative metabolism. Human Papillomavirus (HPV) is the principal etiological agent of cervical cancer. Cervical mucus is a biological system whose main function is the protection of the uterine cervix. This study aims to evaluate the immunomodulatory effect of melatonin on oxidative stress and rheological behavior of cervical mucus. The cervical mucus was analyzed the melatonin concentration, viscosity, superoxide, and the superoxide dismutase. Melatonin showed lower concentration in the cervical mucus from women infected with HPV. The viscosity was lowest in mucus from women infected with oncogenic HPV. The positive samples for HPV also showed high superoxide release and reduced CuZn-SOD levels indicating oxidative stress. Melatonin adsorbed to the polyethylene glycol microsphere (PEG-MLT) was efficient in restoring the viscosity, superoxide anion, and CuZn-SOD at similar levels to mucus from women negative for HPV. These data suggest that in high-risk HPV infections, there is a decrease in melatonin levels and the viscosity of cervical mucus. PEG-MLT was efficient in reducing oxidative stress and restoring viscosity of cervical mucus.
\end{abstract}

Keywords: Oxidative stress, Melatonin, Cervical Mucus, Viscosity, HPV, PEG.

(C) 2020 by the authors. This article is an open-access article distributed under the terms and conditions of the Creative Commons Attribution (CC BY) license (https://creativecommons.org/licenses/by/4.0/).

\section{Introduction}

Human papillomavirus (HPV) is the principal etiological agent of cervical cancer and is a member of the Papillomaviridae family. About 230 types of HPV are known. The types 6 , $11,42,43$, and 44 were related to benign lesions, and types 16, 18, 31, 33, 45, and 66 were associated with high-grade lesions and cancer cervical. Some types of high-risk HPV can stimulate the expression of immunomodulatory agents, which, together with HPV infection, contributes to the appearance of cervical neoplastic lesions [1,2]. Another related parameter in the disease progression of cervical cancer is oxidative stress and an inadequate antioxidant response[3, 4, 5].

The melatonin (MLT) hormone have immunomodulatory properties that are related to the recruitment of leukocytes in infected tissues [6,7], and according to their site of action has 
pro-oxidant or antioxidant activity [8,9]. Alterations in the serum melatonin concentration were observed in the breast, colorectal, endometrial, lung, and stomach cancer [10 - 13]. The antioxidant capacity of melatonin may be related to the direct action on antioxidant enzymes as well as the indirect form on the inhibition of free radicals $[14,15]$.

Reactive oxygen species (ROS) are highly reactive particles, being found as different chemical species, such as superoxide anion $\left(\mathrm{O}_{2}{ }^{-}\right)$, hydrogen peroxide $\left(\mathrm{H}_{2} \mathrm{O}_{2}\right)$, and hydroxyl radical $\left(\mathrm{OH}^{-}\right)[16]$. These molecules are essential intermediaries of mitochondrial respiration, cell signaling, inflammation, and the immune response. Enzymatic antioxidant mechanisms: superoxide dismutase (CuZn-SOD) (EC 1.15.1.1), catalase (CAT) (EC 1.11.1.6), and glutathione (GSH) (EC 1.15.1.9) and non-enzymatic mechanisms: vitamin E, vitamin $\mathrm{C}$, melatonin, lutein and zinc, act to control the ROS concentration, maintaining its physiological levels and minimizing the effects deleterious $[17,18]$. Oxidative stress is the imbalance between the generation of oxidizing compounds and the performance of intrinsic antioxidant systems in cells. The excessive and uncontrolled production of these free radicals can cause molecular alterations in proteins, lipids, carbohydrates, and DNA causing changes in the metabolic activity of these compounds. These alterations result in molecular defects that can lead to several pathologies such as diabetes, obesity, neurodegenerative diseases, and cancer [19 - 21].

Several studies reported a decrease in antioxidants agents or their activities in the blood and uterine cervical cancer [24, 25]. Also observed in the erythrocytes in patients with cervical cancer decreased the activity of CuZn-SOD, CAT, and GSH [22 - 25]. The reduction in SOD activity has been correlated with damage to cellular DNA in cervical tissue infected with HPV. Another factor is related to inflammatory activity, which promotes an increase in ROS levels, associated with a decrease in cellular antioxidant capacity. All these parameters generate a favorable microenvironment for the appearance of neoplastic lesions in infections caused by HPV [26, 27].

On the other hand, rheological studies have shown that deformation and flow of fluids can be associated with certain pathological conditions and influenced by oxidative stress. The characterization of rheological behavior has wide applications in the chemical, food, and pharmaceutical industries, providing important information related to structure and stability $[28,29]$. The viscosity profile of biological fluids such as blood, saliva, bronchial mucus, and cervical mucus has contributed to the understanding of several pathophysiological processes. The characterization of viscosity can also serve as a parameter for the evaluation of the modulating effect of bioactive molecules on the viscosity of biological fluids [29 - 31]. The viscosity of cervical mucus has been analyzed in order to assess sperm motility, hormonal changes during the menstrual cycle, and the production of synthetic cervical mucus [32,33].

Studies have shown that the release of a molecule can be modified when delivered to a carrier system [34- 36]. These systems are capable of improving the parameters of bioavailability, bioavailability, and biofunctionality [28,37]. The association of the melatonin hormone to such delivery systems can potentiate its effect without the need to increase the dosage [36]. Polyethylene glycol microspheres (PEG) are considered an essential vehicle for the administration of drugs, natural products, and hormones [30].

The delivery drugs adsorbed to carrier systems, such as the PEG microspheres has been an efficient alternative treatment in several diseases. Thus these microspheres are promising agents for the delivery of melatonin hormone [38 - 42], preventing it from degradation 
promoted by proteins by metabolic enzymes and mainly increasing their bioavailability in the body [43].

Therefore, this study aimed to assess the correlations between melatonin concentration, the viscosity profile, and oxidative stress of cervical mucus samples infected with HPV modulated with melatonin adsorbed to polyethylene glycol microsphere.

\section{Materials and Methods}

\subsection{Subjects and collection of cervical mucus.}

Cervical mucus samples were collected from women between 18 and 35 years of age who were between the $12^{\text {th }}$ and $21^{\text {st }}$ day of the menstrual cycle without previous history of alterations in the uterine cervix or tested positive for HPV infections. Women that had other diseases such as syphilis, AIDS, diabetes, and cancer were excluded.

Before entering the study, the women signed an informed consent form, which was approved by the local ethics committee (Protocol Number CAAE: 89628218.0.0000.5587).

\subsection{Sample processing.}

The cervical mucus samples were collected using an endocervical brush with a volume of approximately $700 \mu \mathrm{L}$. The samples were centrifuged for the total extraction of the mucus adhered to the brush. The material was fractionated in 2 aliquots, being the first aliquot added $1 \mathrm{~mL}$ of Cell Preserv ${ }^{\circledR}$ (preservative solution) and used directed to the detection of viral DNA, and the second aliquot was used in laboratory analysis.

The rheological analysis was done directly in cervical mucus. For the melatonin levels, superoxide release, and CuZn-SOD, the cervical mucus was previously centrifuged at $1200 \mathrm{x} g$ for 20 minutes and resuspended in $1 \mathrm{~mL}$ of phosphate buffer solution (PBS). The experimental designs are listed in Figure 1.

\subsection{HPV detection.}

The cervical mucus in preservative solution was evaluated detection viral DNA using the Cobas ${ }^{\circledR}$ HPV Test. (Cobas z $480{ }^{\circledR}$ Analyzer - Roche). The test uses the amplification of the target DNA by polymerase chain reaction (PCR) and hybridization of nucleic acid for the detection of 14 high-risk HPV types.

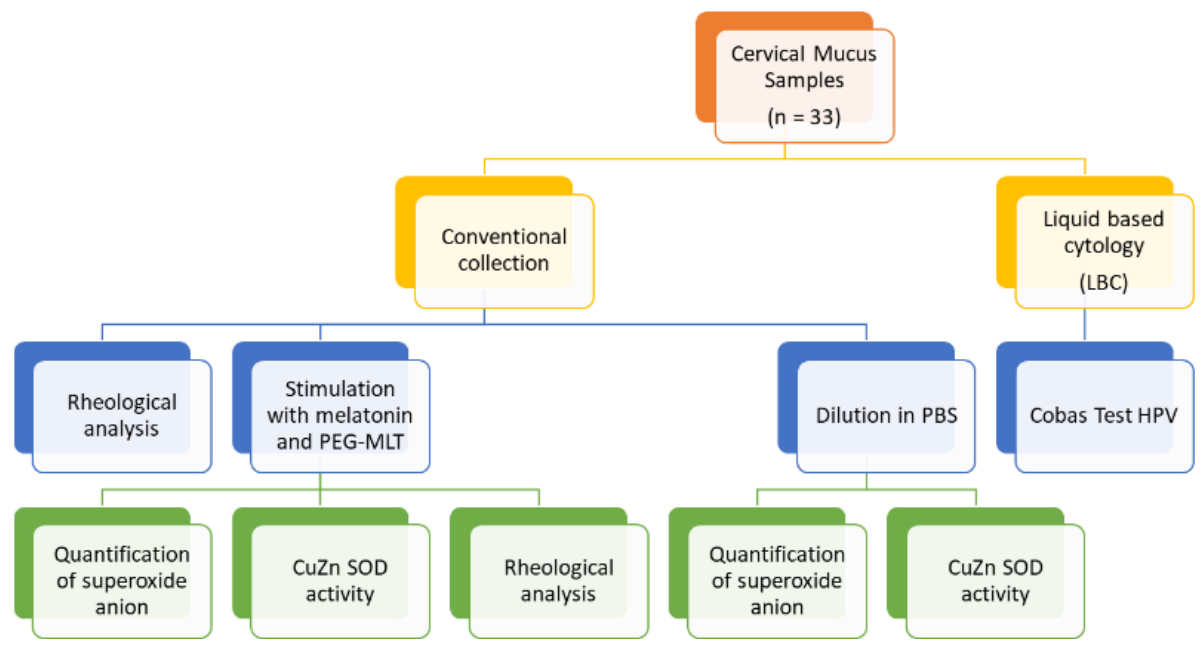

Figure 1. Experimental designs of processing of cervical mucus samples and laboratory analysis. 


\subsection{Melatonin Hormone Quantification.}

The melatonin concentration was performed using the enzyme immunoassay kit of melatonin (Melatonin ELISA® - IBL) [44]. The procedures were performed according to the manufacturer. The reaction rate was measured by absorbance in a spectrophotometer TPReader ${ }^{\circledR}$ microplate reader (Thermo Plate) at $405 \mathrm{~nm}$. Melatonin concentration was calculated as a function of the standard curve in $\mathrm{pg} / \mathrm{mL}$.

\subsection{Formulation and stimulation of melatonin adsorbed to polyethylene glycol (PEG-MLT).}

The melatonin solution at a concentration of $9.0 \mathrm{pg} \cdot \mathrm{mL}^{-1}$ was prepared using PBS for dissolution. The PEG microspheres were used with vehicles to carry the melatonin that was adsorbed on its surface. The microspheres were prepared from PEG 6000, which was diluted in $100 \mathrm{~mL}$ of PBS and incubated for 30 minutes at $37^{\circ} \mathrm{C}$. After incubation, a sodium sulfate solution $\left(\mathrm{Na}_{2} \mathrm{SO}_{4}\right)(\mathrm{v} / \mathrm{v})$ was added to the PEG and incubated at $37{ }^{\circ} \mathrm{C}$ for 45 minutes. The solution was diluted 3:1 in PBS and centrifuged at $5000 \mathrm{rpm}$ for 2 minutes. A further 1:10 dilution in PBS was carried out and incubated at $95{ }^{\circ} \mathrm{C}$ for 5 minutes to obtain medium density microspheres. The microspheres were labeled overnight at room temperature with a solution of Dylight-488 (Pierce Biotechnology, Rockford, USA; $10 \mu \mathrm{g} \cdot \mathrm{mL}^{-1}$ ) in dimethylformamide at a 100:1 molar ratio of PEG:Dylight. The samples were then analyzed by fluorescence microscopy $[41,42]$.

For the formation of the polyethylene glycol microsphere adsorbed with melatonin, the PEG solution mixed with a melatonin solution in the concentration of 9.0 pg.mL-1 and incubated at $37^{\circ} \mathrm{C}$ for 30 minutes $[41,42]$. The PEG-MLT solution was used as a stimulus in the volume of $10 \mu \mathrm{L}$

\subsection{Rheological Analysis.}

In the second aliquot of cervical mucus, part was directed to the rheological analysis of viscosity in a MCR 102 Reometro (Anton Paar®) coupled to the Rheoplus Software v3.61. The shear stress $(\tau)$ was used as a parameter for the test, varying from 0 to $5 \mathrm{mPa}$.s for the upward curve and from 5 to $0 \mathrm{mPa}$.s for the downward curve [29 - 31]. The viscosity of the cervical mucus was reevaluated in all samples after treatment with melatonin and PEG-MLT [melatonin adsorbed to PEG to a final concentration of $100 \mathrm{ng} . \mathrm{mL}^{-1}$ ]. This analysis was repeated after stimulation with PEG-MLT.

\subsection{Superoxide anion.}

Oxidative metabolism was assessed by quantifying the superoxide release in cervical mucus was determined by cytochrome $\mathrm{C}$ reduction [45 - 47]. This colorimetric method consists of the oxidation of ferricytochrome $\mathrm{C}$ in the presence of the superoxide anion, this color change being detectable in a spectrophotometer with a $630 \mathrm{~nm}$ filter.

The cervical mucus was resuspended in PBS containing $2.6 \mathrm{mM} \mathrm{CaCl} 2,2 \mathrm{mM} \mathrm{MgCl}$, and $2 \mathrm{mg} / \mathrm{mL}$ cytochrome C [Sigma, St Louis, USA]. Aliquots [100 $\mu \mathrm{L}$ ] of the suspension were incubated in the presence or not of $10 \mu \mathrm{L}$ of melatonin adsorbed to PEG [PEG-MLT] in culture plates at $37^{\circ} \mathrm{C}$ for 1 hour. After incubation and reading on a spectrophotometer, the superoxide release concentration was calculated using the following relationship:

$$
\left[\mathrm{O}_{2}^{-}\right]=\frac{D O \cdot 100}{6,3}
$$


where, $\left[\mathrm{O}_{2}^{-}\right]$is the concentration of superoxide anion, and $\mathrm{DO}$ is the optical density (absorbance) and the results expressed as $\mathrm{nmol} / \mathrm{O}_{2}{ }^{-}[51]$.

\subsection{CuZn-superoxide dismutase determination (CuZn-SOD - E.C.1.15.1.1).}

The activity of the SOD enzyme was carried out by the method of photo-reduction of nitroblue tetrazolium (NBT). The cervical mucus was diluted in PBS, obtaining a final volume of $0.5 \mathrm{~mL}$, and placed in glass tubes in the presence or not of $10 \mu \mathrm{L}$ of $10 \mu \mathrm{L}$ of melatonin adsorbed to PEG [PEG-MLT]. Each tube contained $0.5 \mathrm{~mL}$ of the sample, and the standard tube contained $0.5 \mathrm{~mL}$ of hydro-alcoholic solution. Next, $0.5 \mathrm{~mL}$ of chloroform-ethanol solution (1:1 ratio) and $0.5 \mathrm{~mL}$ of the reactive mixture (NBT increased by EDTA) was added to the tubes. The experimental and standard solutions received $2.0 \mathrm{~mL}$ of buffer carbonate, and the $\mathrm{pH}$ was increased to 10.2 after the addition of hydroxylamine. The tubes remained still at room temperature for $15 \mathrm{~min}$ and were subsequently read at $560 \mathrm{~nm}$. The following expression calculated superoxide dismutase:

$$
\text { Active SOD }=\frac{(\text { Standard Abs }- \text { Sample Abs })}{(\text { Standard Abs. })} .100
$$

where Abs. Standard is the absorbance of the standard and Abs. The sample is the absorbance of the sample $[48,49]$.

\subsection{Oxidative Stress Index (OxSI).}

The oxidative parameters of the cervical mucus were correlated with the other results through the Oxidative Stress Index (OxSI ) that obtained through the following relationship:

$$
\mathrm{OxSI}=\frac{\text { Active. } \mathrm{SOD}}{\left[\mathrm{O}_{2}^{-}\right]}
$$

Where, $\left[\mathrm{O}_{2}^{-}\right]$is the superoxide concentration and Activ. SOD is the activity of the CuZn-SOD enzyme.

\subsection{Statistical analysis of the data.}

The statistical analysis was performed using the analysis of variance (ANOVA), followed by Tukey's post-test, for the correlation analysis was used the Spearman correlation test. Statistical significance was considered when $\mathrm{p}<0.05$.

\section{Results and Discussion}

\subsection{Sampling and HPV detection.}

The 33 cervical mucus samples analyzed for viral DNA 14 samples were positive for high-risk oncogenic HPV types, and 19 samples were negative being considered as a control group for the subsequent analyzes (Table 1).

Table 1. Detection of human papillomavirus (HPV) in cervical mucus samples.

\begin{tabular}{l|c|c|c}
\multicolumn{1}{c|}{ Cervical Mucus } & Viral types & Number $(\mathbf{n})$ & TOTAL \\
\hline \multirow{2}{*}{ Positive HPV } & HPV 16 & 9 & \multirow{2}{*}{14} \\
\cline { 2 - 3 } & HPV 18 & 4 & 19 \\
\hline Negative HPV & - & 19 & 33
\end{tabular}




\subsection{Melatonin hormone in cervical mucus.}

The melatonin hormone in the cervical mucus of women non-infected showed a concentration of $12.38 \mathrm{pg} . \mathrm{mL}^{-1}$, while in cervical mucus from women infected with HPV presented $6.03 \mathrm{pg} \cdot \mathrm{mL}^{-1}$. There was a decrease of $48.70 \%$ in the melatonin concentration in cervical mucus from women with positive HPV (Figure 2).

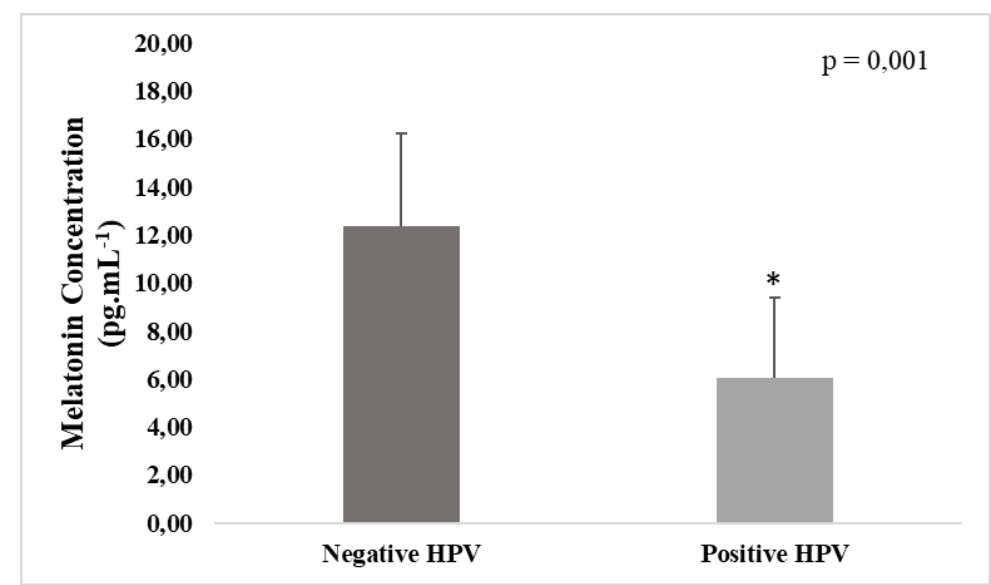

Figure 2. Melatonin concentration in cervical mucus from women with negative and positive for HPV.

*Statistically difference between groups.

There are no records in the scientific literature demonstrating the presence of melatonin in the cervical mucus. It is known that melatonin acts on the female reproductive system, mainly on ovarian function, modulating ovarian steroidogenesis, mainly on progesterone production [50 - 53]. Studies also demonstrate the presence of high concentrations of the hormone in the preovulatory follicles [54]. Other studies also show that the action of melatonin on the gonads [55].In this work, the presence of melatonin in cervical mucus suggests a broad action of this hormone on the female reproductive system.

The vascularization of mucous tissues guarantees them the necessary blood supply to maintain their functions. In the genital mucosa, blood vessels supply nutrients, gas exchange, and hormones [56]. In this work, the presence of melatonin hormone in the cervical mucus may come from the blood circulation itself. Studies show that during the night, occur decrease in the serum melatonin levels in patients with breast, endometrial, prostate, colorectal, lung, and stomach cancer [11-13]. It is known that women with tumor growth have lower serum melatonin levels [57]. In this study, the decrease of melatonin in cervical mucus can be associated with the progression of the lesions.

\subsection{Oxidative stress parameters.}

\subsubsection{Superoxide anion concentration.}

The evaluation of oxidative parameters was performed by quantifying the superoxide anion and the CuZn-SOD enzyme. Oxidative stress is one of the parameters in the disease progression of cervical cancer [58]. Studies have shown a reduction in antioxidant levels in both circulation and uterine tissue of women with cervical cancer [4, 5, 59]. As a result of the decrease in antioxidant levels, there is an increase in reactive oxygen species in the tissues [60]. In this study, we showed a significant increase in the superoxide anion level in the cervical mucus (Figure 3). 


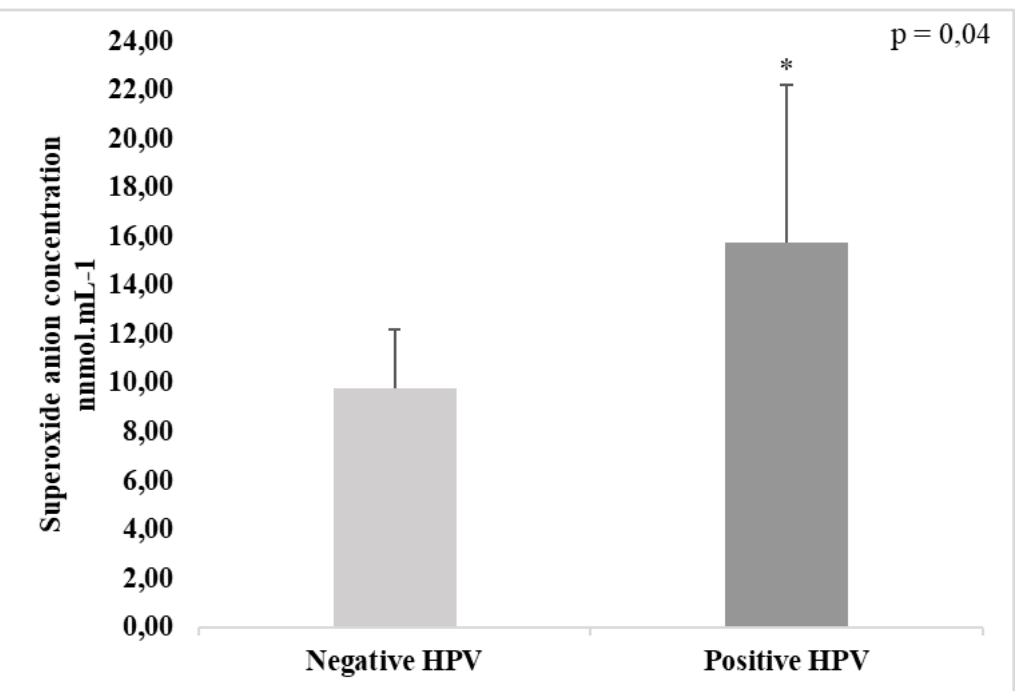

Figure 3. Superoxide anion concentration in cervical mucus from women with negative and positive for HPV.

*Statistically difference between groups.

Reactive species are important cellular signalers in their physiological concentration. However, the increase in these molecules may be related to several diseases. The consequence of the increase in free radicals is damage to DNA. In infections caused by HPV-16, free radicals promote the activation of the E7 oncogene, which in turn leads to genomic instability and promotes replication [61]. Thus, both the increase in ROS and the inhibition of antioxidant agents are molecular devices for the progression of infection and, consequently, cancer.

HPV infections occur through the viral insertion to the basal epithelial layer, the particularly mentally squamocolumnar junction (SCJ), or in regions of micro lesions generated during sexual intercourse [62]. The increase in the superoxide anion in cervical mucus from women infected for HPV points to an oxidative imbalance in the uterine cervix. It is not yet known whether this oxidative imbalance induced or promoted the evolution of infection.

\subsubsection{CuZn-SOD enzyme determination.}

SOD acts as a central enzyme for the metabolism of the superoxide anion, being of fundamental importance for the balance of the cell-mediated immune response [63].

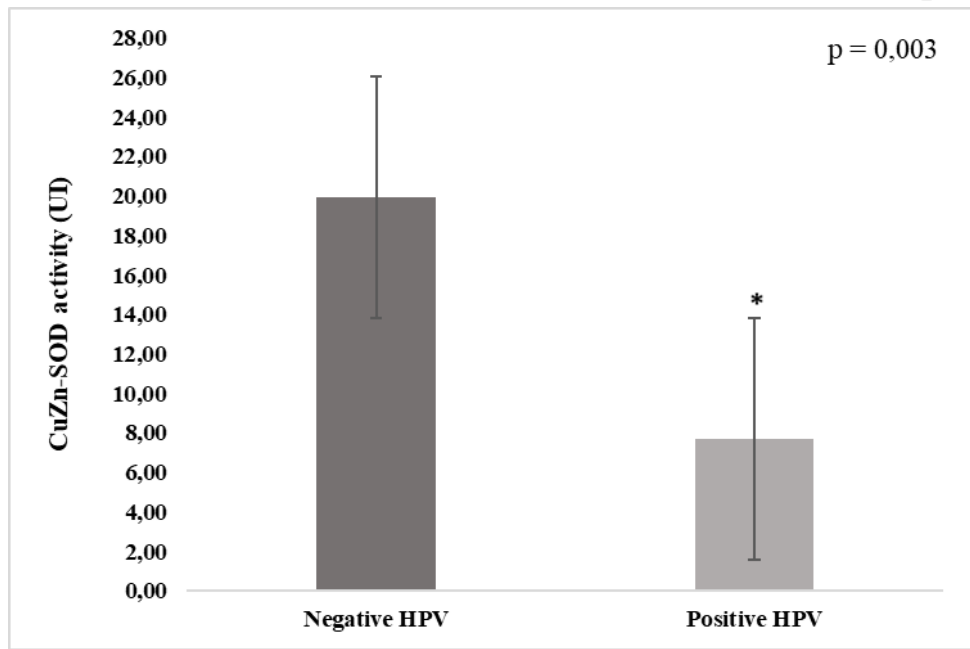

Figure 4. Activity of the CuZn-SOD enzyme in cervical mucus from women with negative and positive for HPV. *Statistically difference between groups.

The impairment of the antioxidant functions of cells, due to the decreased activity of the SOD enzyme, is related to several diseases and neoplasms [64, 65]. Insufficient 
concentrations of enzymatic cofactors, such as zinc and manganese, can lead to a reduction in SOD [66]. Studies have reported a significant decrease in CuZn-SOD activity in the uterine cervix in patients with cervical cancer [28]. In this study, we observed a lower SOD concentration in cervical mucus from women with positive HPV (Figure 4).

The decrease in SOD in the uterine cervix was demonstrated in other studies [26], and the cervical mucus, evidenced in this work, may probably be due to oxidative stress in the microenvironment of the uterine cervix in patients with cervical cancer. This oxidative imbalance does not necessarily reflect systemic oxidative stress, once it has been observed that the plasma alterations SOD activity are not related to those found in tissues [67, 68]. This particularity corroborates the importance of studying the oxidative parameters of cervical mucus.

\subsubsection{Oxidative stress index.}

Since the concentration of superoxide anion and the activity of CuZn-SOD are an essential parameter for the assessment of oxidative stress, the relationship between these two variables was expressed in the form of the Oxidative Stress Index (OxSI). Thus, the OxSI value is directly proportional to the antioxidative response; that is, the higher the index value, the greater the SOD activity or, the lower the concentration of the superoxide anion, with both events co-occurring.

Comparing the OxSI values, the cervical mucus from women infected by HPV showed a lower index value compared to the women without the infection (Table 2). This results in reinforce the hypothesis that the cervical mucus from women with positive HPV present the oxidative imbalance once that these groups showed higher superoxide concentration and lower SOD activity (Figures 3 and 4). This behavior has been observed in HPV infections and uterine cervical cancer $[23,65,66]$.

Some studies have shown that CuZn-SOD, unlike Mn-SOD, which is mitochondrial, does not respond directly to oxidative stress because of its action mediated by indirect mechanisms [67, 69]. Thus, the increase in the superoxide anion in the cervical mucus does not directly stimulate the activity of CuZn-SOD in the site.

Table 2. Oxidative Stress Index (OxSI) from cervical mucus form women.

\begin{tabular}{l|c} 
GROUPS & OxSI \\
\hline Negative HPV & $1,44 \pm 0,72$ \\
\hline Positive HPV & $0,76 \pm 0,41^{*}$ \\
$*$ Statistically difference between groups.
\end{tabular}

Here, the difference between the OxSI values between the studied groups can be due to the higher melatonin levels of cervical mucus showed in women with HPV infection. The melatonin hormone has a direct action on the regulation of oxidative activity.

\subsection{Rheological analysis.}

However, cervical mucus is the first physical barrier to protect the uterine cervix against infections [70]. The loss of the rheological characteristics of this fluid makes the cervix susceptible to biological and physical harmful action [71]. Several studies have classified the rheological characteristics of cervical mucus according to the ovulatory cycle, hormonal action, and pathological state [72]. The mucus viscosity is also related to the characteristics of fertility and sperm mobility [73]. 
In this work, was observed a decrease of viscosity in cervical mucus from women infected with HPV (Figure 5). This decrease in viscosity may action the uterine cervix and favor to viral infection. Studies have shown that the viscosity of cervical mucus decreases due to the action of the hormone estrogen [74 - 77]. Estrogen is the main female hormone responsible for the control of the ovulatory cycle [75].

On the other hand, melatonin can act directly on the production of estrogen and neoplastic growth by inhibiting the activity of the enzyme aromatase (converts androgens into estrogens) and by the specific endogenous inhibition of alpha estrogen receptors via calmodulin estrogen [74 - 77]. Thus melatonin acts as a modulator of estrogen production. The higher concentrations of melatonin in women without HPV infection suggest a protective effect that probably maintains the physiological levels of estrogen and viscosity. However, in women with HPV-infected low melatonin levels, possibly occur an increase in estrogen concentrations, which can be related to a decrease in the viscosity. Further studies should be conducted to understand better hormonal involvement and changes in viscosity in cervical mucus.

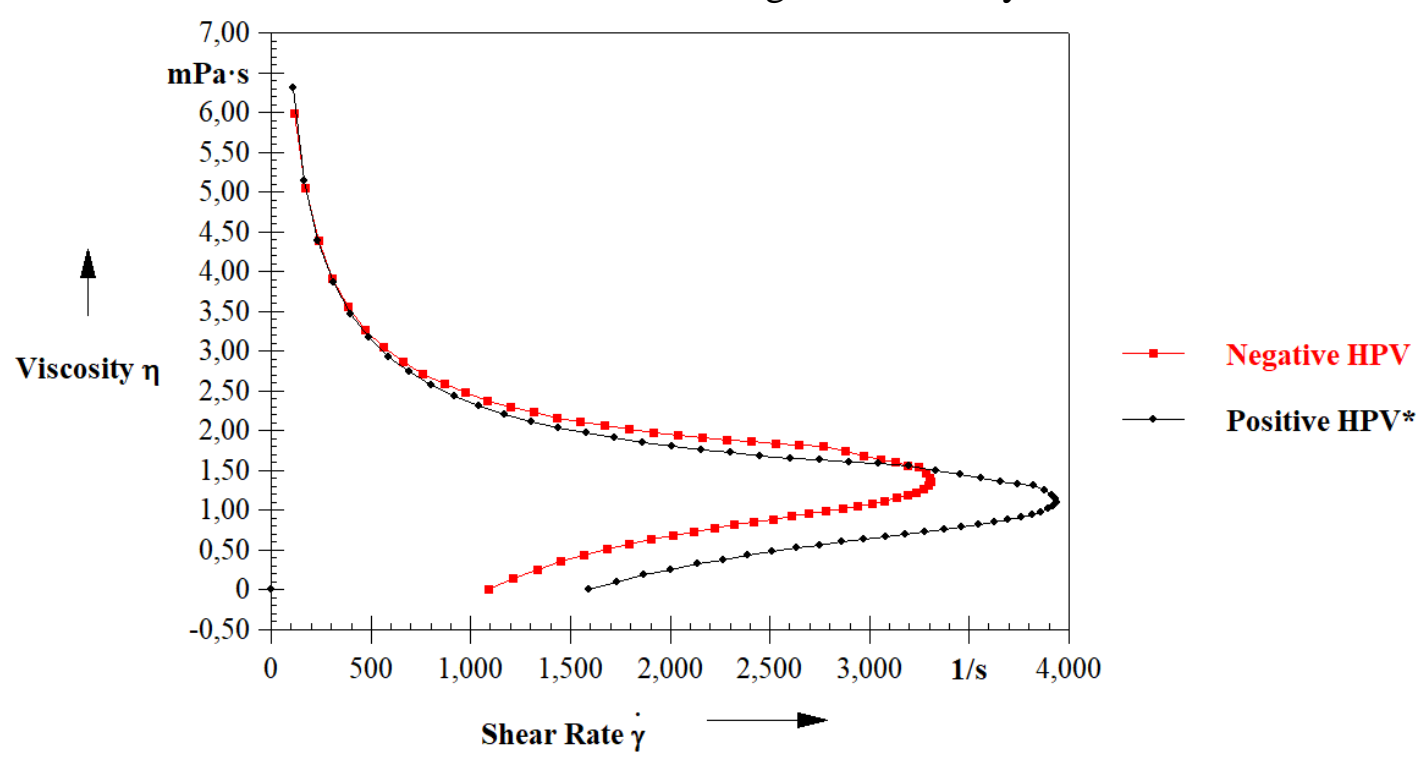

Figure 5. Viscosity curve of the cervical mucus from women with negative and positive for HPV. *Statistically difference between groups.

\subsection{Stimulation with melatonin and PEG-MLT.}

In order to minimize and oxidative damage caused by the action of HPV infection on cervical mucus, by decreasing the concentration of melatonin, the cervical mucus samples were treated with melatonin [MLT] at a concentration of $9 \mathrm{pg} \cdot \mathrm{mL}^{-1}$ adsorbed or not to polyethylene glycol microsphere [PEG-MLT].

After stimulation of the cervical mucus samples, measurements of superoxide anion, activity of the CuZn-SOD enzyme, and viscosity curve were performed, and the results correlated with the OxSI.

Independently of HPV infection, similar superoxide concentration was observed in the cervical mucus when in the presence of melatonin. The treatment with PEG-MLT in cervical mucus from women infected by HPV reduced in $27.3 \%$ the superoxide concentration (Figure 6). These results can be explained by the significant increase in the activity of the SOD CuZn enzyme. Melatonin, adsorbed or not to PEG, was able to increase the activity of the CuZnSOD enzyme in cervical mucus. The highest CuZn-SOD activities were observed in cervical mucus treated with PEG-MLT from women with HPV infection (Figure 7). 


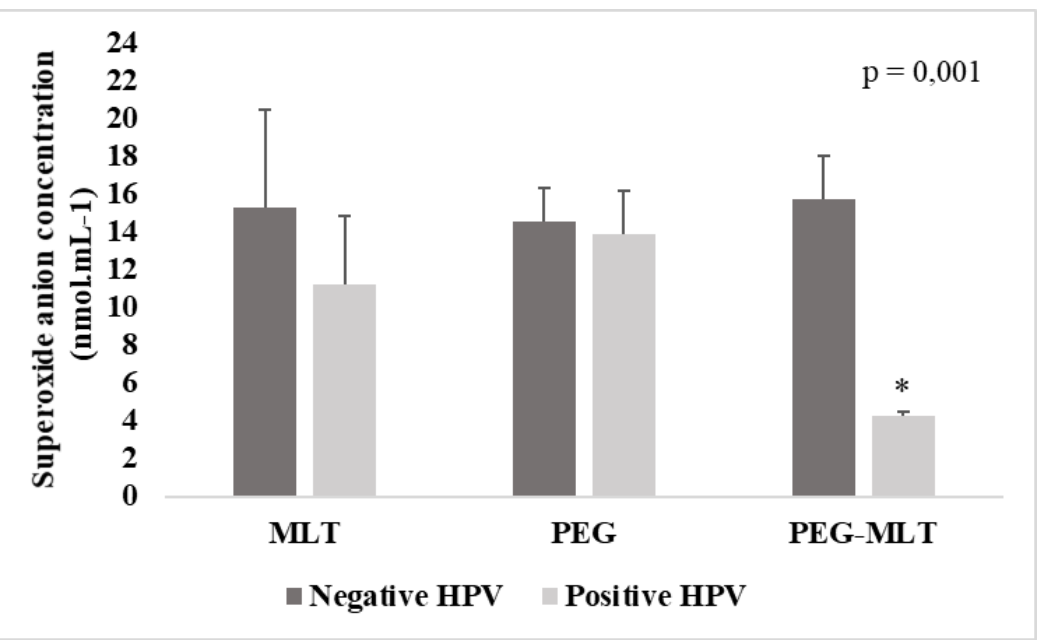

Figure 6. Superoxide anion concentration in cervical mucus after treatment with melatonin adsorbed or not to PEG microsphere from women with negative or positive for HPV. Note: MTL (melatonin); PEG (Polyethylene glycol); PEG-MLT (melatonin adsorbed to Polyethylene glycol) *Statistically different between groups.

Several studies highlight the antioxidant activity of melatonin, both acting directly on free radicals and indirectly through the modulation of enzyme activity [9, 10, $78-80]$. The results presented in Figures 6 and 7 reinforce the antioxidant effects of melatonin, as well as the action of the PEG microsphere that slows the degradation and prolonging the effect of this hormone [34, 38, 39]. Another fact is that the adsorption of several melatonin molecules on the surface of the PEG microsphere increases in the bioavailability of melatonin [39 - 43].

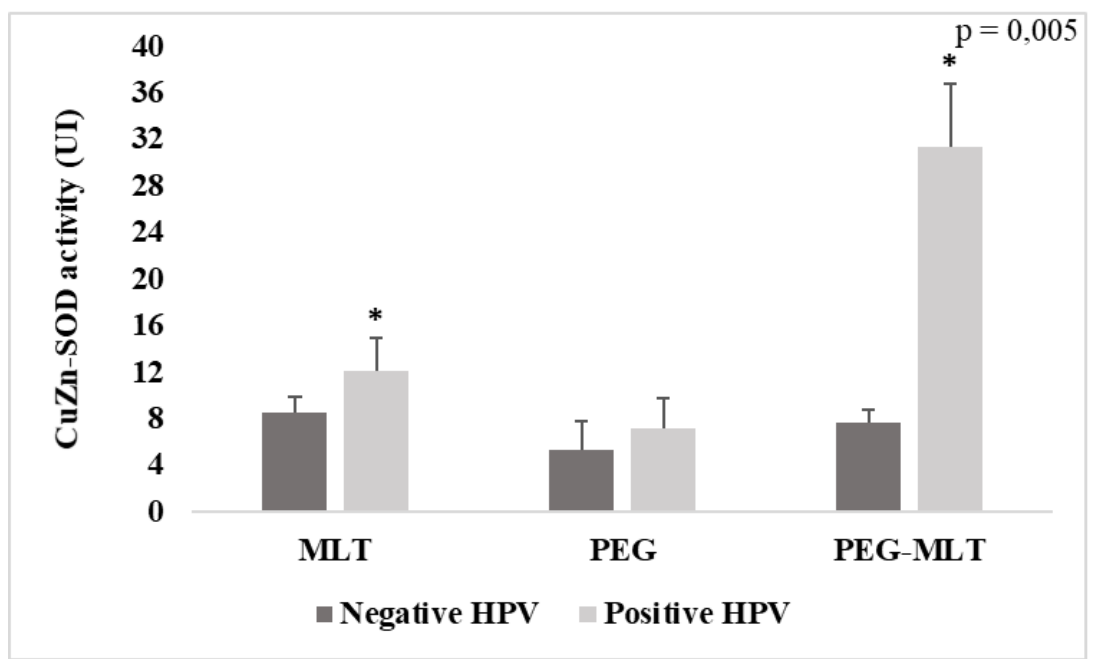

Figure 7. CuZn-SOD enzyme activity in cervical mucus after treatment with melatonin adsorbed or not to PEG microsphere from women with negative or positive for HPV. Note: MTL (melatonin); PEG (Polyethylene glycol); PEG-MLT (melatonin adsorbed to Polyethylene glycol) *Statistically different between groups.

Through the rheological analysis, it was possible to observe an increase in the viscosity of cervical mucus from women infected by HPV when treated with PEG-MLT (Figure 8). The microsphere adsorbed to melatonin was able to restore the viscosity of the cervical mucus from women with positive for HPV to values similar to those observed in cervical mucus from women negative for HPV.

Due to the fact that cervical mucus is a protective barrier of the uterine cervix against physical and biological agents $[5,81]$, the restoration of its viscosity can be significant for the control of infection and probably can act in the prevention of cancer of cervical uterine. 


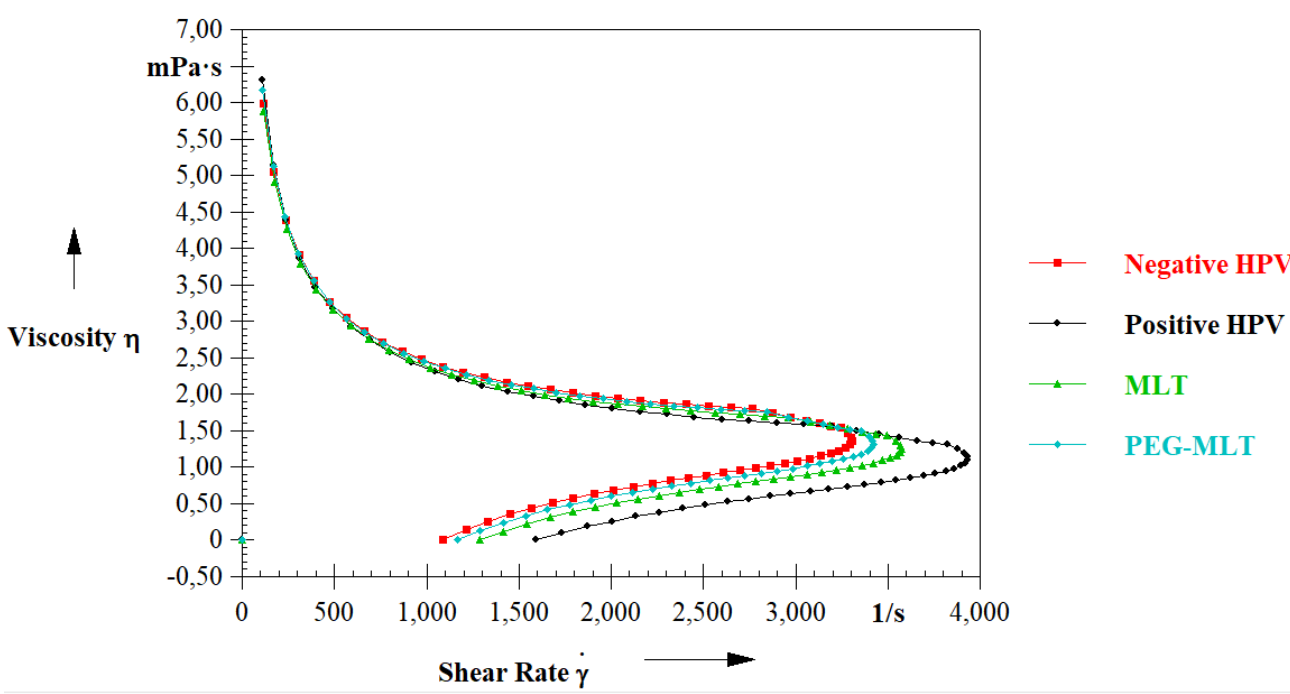

Figure 8. Viscosity curve of cervical mucus after treatment with melatonin adsorbed or not to PEG microsphere from women with negative or positive for HPV. Note: MTL (melatonin); PEG (Polyethylene glycol); PEG-MLT (melatonin adsorbed to Polyethylene glycol) *Statistically different between groups.

By correlating the OxSI and the melatonin concentration in the cervical mucus after stimulation with PEG-MLT, it was possible to observe a significant increase in the $r$-value $(r=$ 0.32- Table 3). The positive correlation of these parameters reinforces the hypothesis that the increase in the concentration of melatonin provides an increase in OxSI, as shown in Figures 5 and 6 by the decrease in superoxide release levels and the increase in SOD activity. The higher $r$-value obtained in the correlation test demonstrates the efficiency of the PEG microsphere in potentiating the effects of the carried compounds, a result confirmed in other studies [39 - 43]. OxSI showed no correlation with melatonin concentration for the control group.

Interesting that in this study, the data were correlated. Spearman's correlation analysis showed that melatonin concentration is directly proportional to OxSI; being this correlation is ten times higher in cervical mucus from women with positive HPV (Table 3). This effect is explained by the direct action of melatonin on the superoxide anion, chelating it through HaberWeiss reactions, described for this hormone [69, 78 - 80].

Table 3. Spearman's correlation test between melatonin concentration and OxSI of cervical mucus from women with negative or positive for HPV.

\begin{tabular}{l|l|l} 
GROUPS & $\boldsymbol{r}$-value & $\boldsymbol{p}$-value* \\
\hline Negative HPV & $+0,02$ & 0,04 \\
\hline Positive HPV & $+0,20$ & 0,04 \\
\hline Negative HPV+ PEG-MLT & $+0,05$ & 0,06 \\
\hline Positive HPV + PEG-MLT & $+0,32$ & 0,03
\end{tabular}

Note: MTL (melatonin); PEG (Polyethylene glycol); PEG-MLT (melatonin adsorbed to Polyethylene glycol) *Statistically different between groups.

The correlation established between viscosity and OxSI showed the protective effect of the antioxidant mechanism on cervical mucus. The non-infected group showed a positive correlation between the variables, indicating that the antioxidant efficiency contributes to maintaining the increase in cervical mucus viscosity. (Table 4). The cervical mucus infected by HPV did not show a correlation between the variables, showing that the decrease in viscosity in this group occurs due to the action of melatonin [74].

The correlation between OxSI and viscosity, after stimulation with PEG-MLT, was directly proportional. Thus, as the OxSI value increases, the viscosity value increases. Such an 
effect may be correlated with the effect of melatonin probably by estrogen alterations $[50,52$, 76].

Table 4. Spearman's Correlation Test between OxSI and the viscosity of cervical mucus from women with negative or positive for HPV.

\begin{tabular}{l|c|l} 
GROUPS & $\boldsymbol{r}$-value & $\boldsymbol{p}$-value* \\
\hline Negative HPV & $+0,51$ & 0,04 \\
\hline Positive HPV & $+0,05$ & 0,80 \\
\hline Negative HPV+ PEG-MLT & $-0,15$ & 0,07 \\
\hline Positive HPV + PEG-MLT & $+0,31$ & 0,03
\end{tabular}

Note: MTL (melatonin); PEG (Polyethylene glycol); PEG-MLT (melatonin adsorbed to Polyethylene glycol) *Statistically different between groups.

\section{Conclusions}

We conclude that the hormone melatonin is present in cervical mucus and that this concentration is lower in cervical mucus from women with HPV infection. The cervical mucus infected by HPV shows a reduction in the activity of SOD-CuZn and an increase in the superoxide anion concentration.

It was possible to establish a directly proportional correlation between the concentration of melatonin and the activity of the enzyme CuZn-SOD. In contrast, melatonin showed an inversely proportional correlation with the superoxide anion. OxSI was efficient in assessing the impairment of antioxidant functions generated by HPV infection, which is directly correlated to the melatonin concentration.

In high-risk HPV infections, there is a decrease in the viscosity of cervical mucus. The melatonin concentrations were directly correlating to the viscosity of cervical mucus. PEGMLT was efficient in reducing oxidative stress by increasing SOD activity and decreasing the concentration of superoxide anion. PEG-MLT was efficient in restoring viscosity of cervical mucus from women infected for HPV.

\section{Funding}

This research was funded by Coordination for the Improvement of Higher Education Personnel(CAPES) and the National Council for Scientific and Technological Development (CNPq No: 447218/2014-0; No: 305725/2018-1), Brazil.

\section{Acknowledgments}

We are grateful to the Chronoimmunomodulation Laboratory ofFederal University of Mato Grosso - UFMT/Brazil and to the Laboratory of Immunology, Molecular Biology and Bioassays at the Federal University of Mato Grosso do Sul - UFMS/Brazil for technical and logistical support.

\section{Conflicts of Interest}

The authors declare no conflict of interest and non-financial competing interests regarding the publication of this article. 


\section{References}

1. Prata, T.T.M.; Bonin, C.M.; Ferreira, A.M.T.; Padovani, C.T.J.; Fernandes, C.E.D.S.; Machado, A.P.; Tozetti, I.A. Local immunosuppression induced by high viral load of human papilloma virus: characterization of cellular phenotypes producing interleukin-10 in cervical neoplasticlesions. Immunology 2015, 146, 113-121, https://doi.org/10.1111/imm.12487.

2. Kobayashi, A.; Weinberg, V.; Darragh, T.; Smith-McCune, K. Evolving immunosuppressive microenvironment during human cervical carcinogenesis. Nature 2008, 1, 412-420, https://doi.org/10.1038/mi.2008.33.

3. Calaf, G. M.; Urzua, U.; Termini, L.; Aguayo, F. Oxidative stress in female cancers. Oncotarget 2018, 9, 23824-23842, https://doi.org/10.18632/oncotarget.25323.

4. Balasubramaniyan, N.; Subramanian, S.; Govindasamy, S. Status ofantioxidant systems in human carcinoma of uterine cervix. Cancer Let. 1994, 87, 187-192, https://doi.org/10.1016/0304-3835(94)90221-6.

5. Maldonado, P.A.; Negrini, L.A.; Kaizer, R.R.; Zanin, R.F.; do CarmoAraújo, M.; Battisti, V.; Schetinger, M.R.C. Oxidative status in patients submitted to colonization and radiation treatments for uterine cervix neoplasia. Clin. Chim. Acta 2006, 366, 174-178,https://doi.org/10.1016/j.cca.2005.09.025.

6. Golan, K.; Kollet, O.; Markus, R.P.; Lapidot, T. Daily light and darkness onset and circadian rhythms metabolically synchronize hematopoietic stem cell differentiation and maintenance: The role of boné marrown or epinephrine, TNF and melatonin cycles. Exp. Hematol. 2019, 78, 1-10, https://doi.org/10.1016/j.exphem.2019.08.008.

7. Maestroni, G.J. The immunotherapeutic potential of melatonin. Curr. Opin. Invest Dr. 2001, 10, 467476,https://doi.org/10.1517/13543784.10.3.467.

8. Sánchez-Sánchez, A M.; Martín, V.; García-Santos, G.; Rodríguez-Blanco, J.; Casado-Zapico, S.; SuarezGarnacho, S.; Rodriguez, C. Intracellular redox state as determinant for melatonin antiproliferative vs cytotoxic effects in cancer cells. Free Radic. Res. 2011, 45, 1333-1341, https://doi.org/10.3109/10715762.2011.623700.

9. Fernandes, R.T.S.; França, E.L.; Fagundes-Triches, D.L.G.; Fujimori, M.; Machi, P.G.F.; Massmman, P.F.; Tozetti, I.A.; Honorio-França, A.C. Nanodoses of melatonin induces apoptosis on human breast cancer cells co-cultured with colostrum cells. Biointerface Res. Appl. Chem. 2019, 9, 4416-4423, https://doi.org/10.33263/BRIAC95.416423

10. Bartsch, C.; Bartsch, H.; Bellmann, O.; Lippert, T.H. Depression of serum melatonin in patients with primary breast câncer is not due to an increased peripheral metabolism. Cancer 1991, 67, 1681-1684, https://doi.org/10.1002/1097-0142(19910315)67:6<1681::aid-cncr2820670634>3.0.co;2-0.

11. Bartsch, C.; Bartsch, H.; Schmidt, A.; Ilg, S.; Bichler, K.H.; Flüchter, S.H. Melatoninand 6-sulfatoxy melatonin circadian rhythms in serum and urine of primary prostate câncer patients: evidence for reduced pineal activity and relevance of urinary determinations. Clin. Chim. Acta 1992, 209, 153-167, https://doi.org/10.1016/0009-8981(92)90164-L.

12. Gonzalez-Candia, A.; Veliz, M.; Carrasco-Pozo, C.; Castillo, R.L.; Cárdenas, J.C.; Ebensperger, G.; Herrera, E.A. Antenatal melatonin modulates na enhanced antioxidant/pro-oxidant ratio in pulmonary hypertensive newborn sheep. Redox Biol. 2019, 22, 1-11,https://doi.org/10.1016/j.redox.2019.101128.

13. Khoory, R.; Stemme, D. Plasma melatonin levels in patients suffering from colorectal carcinoma. J. Pineal Res. 1988, 5, 251-258,https://doi.org/10.1111/j.1600-079x.1988.tb00651.x.

14. Klepac, N.; Rudeš, Z.; Klepac, R. Effects of melatonin on plasma oxidative stress in rats with streptozotocin induced diabetes. Biomed. Pharmacother. 2006, 60, 32-35, https://doi.org/10.1016/j.biopha.2005.08.005.

15. Sudnikovich, E.J.; Maksimchik, Y.Z.; Zabrodskaya, S.V.; Kubyshin, V.L.; Lapshina, E.A.; Bryszewska, M.; Zavodnik, I.B. Melatonin attenuates metabolic disorders due to streptozotocin-induced diabetes in rats. Eur. J. Pharmacol. 2007, 569, 180-187,https://doi.org/10.1016/j.ejphar.2007.05.018.

16. Bianchi, M.D.L.P.; Antunes, L.M.G. Radicais livres e os principais antioxidantes da dieta. Rev. Nutr.1999, 12, 123-130,https://doi.org/10.1590/S1415-52731999000200001.

17. Lin, X.; Dai, Y.; Tong, X.; Xu, W.; Huang, Q.; Jin, X.; Zhang, S. Excessive oxidative stress in cumulus granulosa cells induced cell senescence contributes to endometriosis-associated infertility. Redox Biol.2020, 30, 1-13, https://doi.org/10.1016/j.redox.2020.101431.

18. Prasad, A.S.; Beck, F.W.; Bao, B.; Fitzgerald, J.T.; Snell, D.C.; Steinberg, J.D.; Cardozo, L.J. Zinc supplementation decreases incidence of infections in the elderly: effect of zinc on generation of cytokines and oxidative stress. Am. J. Clin. Nutr.2007, 85, 837-844,https://doi.org/10.1093/ajcn/85.3.837.

19. Guillaumet-Adkins, A.; Yañez, Y.; Peris-Diaz, M.D.; Calabria, I.; Palanca-Ballester, C.; Sandoval, J. Epigenetics and oxidative stress in aging. Oxi. Med. Cell Longev. 2017, 2017, 1-8, https://doi.org/10.1155/2017/9175806.

20. Fujimori, M., França, E.L, Fiorin, V., Morais, T.C., Honorio-França, A.C., Abreu, L.C. Changes in the biochemical and immunological components of serum and colostrum of overweight and obese mothers. BMC Pregnancy Childb..2015,15, 166. https://doi.org/10.1186/s12884-015-0574-4.

21. Marco, F. Oxidative stress and HPV carcinogenesis. Viruses 2013, 5, 708731,https://doi.org/10.3390/v5020708. 
22. Kolanjiappan, K.; Manoharan, S.; Kayalvizhi, M. Measurement of erythrocyte lipids, lipid peroxidation, antioxidants and osmotic fragility in cervical cancer patients. Clin. Chim. Acta 2002, 326, 143-149, https://doi.org/10.1016/S0009-8981(02)00300-5.

23. Manju, V.; Sailaja, J.K.; Nalini, N. Circulating lipid peroxidation and antioxidant status in cervical câncer patients: a case-controlstudy. Clin. Biochem. 2002, 35, 621-625,https://doi.org/10.1016/S00099120(02)00376-4.

24. Manoharan, S.; Kolanjiappan, K.; Kayalvizhi, M.; Sethupathy, S. Lipid peroxidation and antioxidant status in cervical câncer patients. J. Biochem. Mol. Biol. Biophys. 2002, 6, 225-227.

25. Ebrahimi, S.; Soltani, A.; Hashemy, S.I. Oxidative stress in cervical cancer pathogenesis and resistance to therapy. J. Cell. Biochem. 2019, 120, 6868-6877, https://doi.org/10.1002/jcb.28007.

26. Srivastava, S.; Natu, S. M.; Gupta, A.; Pal, K.A.; Singh, U.; Agarwal, G.G.; Srivastava, A.N. Lipid peroxidation and antioxidants in different stages of cervical cancer: Prognostic significance. Indian J. Cancer 2009, 46, 297-302. https://doi.org/10.4103/0019-509X.55549.

27. Williams, V.M.; Filippova, M.; Soto, U.; Duerksen-Hughes, P.J. HPV-DNA integration and carcinogenesis: putative roles for inflammation and oxidative stress. Future Virol 2011, 6, 45-57, https://doi.org/10.2217/fvl.10.73.

28. Huang, N. Rheological Characterization of Pharmaceutical and Cosmetic Formulations for Cutaneous Applications. Curr. Pharm. Des. 2019, 25, 2349-2363, https://doi.org/10.2174/1381612825666190716110919.

29. Ribeiro, E.B.; Lanes, P.K.D.; Chaud, N.G.A.; Pessoa, R.S.; Honorio-França, A.C.; França, E.L. Microemulsions with levamisole delivery systems as novel immunomodulating agents with potential for amebiasis therapies. Sci. Adv. Mater. 2015, 7, 15-27, https://doi.org/10.1166/sam.2015.2003.

30. Silva, F.H., Ribeiro, A.A.L.; Deluque, A.L.; Cotrim, A.C.M.; de Marchi, P.G.F.; França, E.L.; HonorioFranca, A.C. Effects of barium chloride adsorbed to polyethyleneglycol (PEG) microspheres on co-culture of human blood mononuclear cell and breast câncer cell lines (MCF-7). Immunopharmacol Immunotoxicol. 2018, 40, 18-24, https://doi.org/10.1080/08923973.2017.1392563.

31. Fernandez-Hermida, Y.; Grande, G.; Menarguez, M.; Astorri, A.L.; Azagra, R. Proteomic markers in cervical mucus. Protein Peptide Lett. 2018, 25, 463-471,https://doi.org/10.1186/s12976-018-0092-y.

32. Burruano, B.T.; Schnaare, R.L.; Malamud, D. Synthetic cervical muçus formulation. Contraception 2002 , 66, 137-140,https://doi.org/10.1016/s0010-7824(02)00336-0.

33. Kirkman-Brown, J.C.; Smith, D.J. Sperm motility: is viscosity fundamental to progress? Mol. Hum. Reprod.2011, 17, 539-544, https://doi.org/10.1093/molehr/gar043.

34. Scherer, E.F; Honorio-França, A.C Hara, C.CP; Reinaque, A.P.B.; Côrtes, M.A.; França, E L. Immunomodulatory effects of poly (ethylene glycol) microspheres adsorbed with nanofractions of Momordica charantia L. on diabetic human blood phagocytes. Sci. Adv. Mater 2011, 3, 687-694, https://doi.org/10.1166/sam.2011.1236.

35. França, E.L.; Honório-França, A.C.; Fernandes, R.T.; Marins, C.M.; Pereira, C.C.; Varotti, F.P. The Effect of Melatonin Adsorbed to Polyethylene Glycol Microspheres on the Survical of MCF-7 Cells. Neuroimmunomodulation, 2015, 23, 27-32,https://doi.org/10.1159/000439277.

36. Ribeiro, E.B.; Marchi, P.G.F.; Honorio-França, A.C.; França, E.L.; Soler, M.A.G. Interferon-gamma carrying nanoemulsion with immunomodulatory and anti-tumour activity. J. Biomed. Mater. Res.2019,112, https://doi.org/10.1002/jbm.a.36808.

37. Murugan, N.; Natarajan, D. Bionanomedicine for antimicrobial therapy - a case study from Glycosmis pentaphylla plant mediated silver nanoparticles for control of multidrug resistant bacteria. Lett. Appl. NanoBioScience, 2018, 8, 523-540. https://doi.org/10.33263/LIANBS834.523540.

38. Reinaque, A.P.B.; França, E.L.; Scherer, E.F.; Côrtes, M.A.; Souto, F.J.D.; Honorio-França, A.C. Natural material adsorbed onto a polymer to enhance immune function. Drug Des. Devel. Ther.2012, 6, 209216,https://doi.org/10.2147/DDDT.S34622.

39. Fagundes, D.L.G.; Franca, E.L.; Hara, C.D.C.P.; Honorio-Franca, A.C. Immunomodulatory Effects of Poly (Ethylene Glycol) Microspheres Adsorbed with Cortisol on Activity of Colostrum Phagocytes Int. J. Pharmacol.2012, 8, 510-518,https://doi.org/10.3923/ijp.2012.510.518.

40. Guimarães, P.C.L.; Honorio-França, A.C.; Hara, C.d.C.P.; Fagundes, D.L.G.; Ratto, S.H.B.; França, E.L. Modulation of human colostrum phagocyte activity by the glycine-adsorbed polyethyleneglycol microspheres. J. Chem. 2013, 2013, 1-8, http://dx.doi.org/10.1155/2013/845270.

41. Hara, C.C.P.; Honorio-França, A.C.; Fagundes, D.L.G.; Guimarães, P.C.L.; França, E.L. Melatonin nanoparticles adsorbed to polyethyleneglycol microspheres as activators of human colostrum macrophages. J. Nanomater.2013, 2013, 1-8, https://doi.org/10.1155/2013/973179.

42. Fernandes R.T.S; Cotrim, A.C.M.; França, E.L.; Honorio-França, A.C.; Tozetti, I.A. Melatonin bioengineered: A New Possible Strategy for Treatment of Breast Cancer. Int. J. Adv. Eng. Res. Sci2018, 5, 9-18,https://doi.org/10.22161/ijaers.5.10.2.

43. Yu, D.; Peng, P.; Dharap, S. S.; Wang, Y.; Mehlig, M.; Chandna, P.; Borchard, G. Antitumor activity of poly (ethylene glycol)-camptothecin conjugate: The inhibition of tumor growth in vivo. J. Control. Release 2005 , 110, 90-102, https://doi.org/10.1016/j.jconrel.2005.09.050. 
44. Morceli, G.; Honorio-França, A.C.; Fagundes, D.L.G.; Calderon, I.M.P.; França, E.L. Antioxidant effect of melatonin on the functional activity of colostral phagocytes in diabetic women. PLos ONE 2013, 8, 1-8, https://doi.org/10.1371/journal.pone.0056915.

45. Araújo, R.L.; Savazzi, S.; Fujimori, M.; Deluque, A.; Honório-França, E.L.; Pertuzatti Konda, P.B.; Honório-França, A.C. Effects of Mangaba (Hancornia speciosa) Fruit Extract Adsorbed onto PEG Microspheres in MCF-7 Breast Cancer Cells Co-Cultured with Blood Cells. Asian Pac. J. Cancer Prev. 2019, 20, 1995-2001,https://doi.org/10.31557/APJCP.2019.20.7.1995.

46. Novelli, E.L.; Rodríguez, N.L.; França, E.L.; Gebra, L.M.N.; Ribas, B.O. High Dietary Carbohydrate and Panceatic lesion. Braz. J Med. Biol Res.1993, 26, 31-36.

47. Pick, E.; Mizel, D. Rapid microassays for the measurement of superoxide and hydrogen peroxide production by macrophages in culture using an automatic enzyme immunoassay reader. J. Immunol. Methods 1981, 46, 211-226,https://doi.org/10.1016/0022-1759(81)90138-1.

48. Honorio-Franca, A.C.; Carvalho, M.P.S.M.; Isaac, L.; Trabulsi, L.R.; Carneiro-Sampaio, M.M.S. Colostral mononuclear phagocytes are able to kill enteropathogenic Escherichia coli opsonized with colostral IgA. Scand. J. Immunol.1997, 46, 59-66, https://doi.org/10.1046/j.1365-3083.1997.d01-86.x.

49. Morais, C.T.; Honorio-França, C.A.; Fujimori, M.; de Quental, B.O.; Pessoa, S.R.; França, L.E.; de Abreu, C.L. Melatonin action on the activity of phagocytes from the colostrum of obese women. Medicina 2019, 55, 1-11, https://doi.org/10.3390/medicina55100625.

50. Dair, E.L.; Simoes, R.S.; Simões, M.J.; Romeu, L.R.G.; Oliveira-Filho, R.M.; Haidar, M.A.; Baracat, E.C.; Soares, J.M., Jr. Effects of melatonin on the endometrial morphology and embryo implantation in rats. Fertil. Steril. 2008, 89, 1299-1305, https://doi.org/10.1016/j.fertnstert.2007.03.050.

51. Masana, M.I.; Soares Jr, J.M.;Dubocovich, M.L. 17 $\beta$-estradiol modulates hMT1 melatonin receptor function. Neuroendocrinology 2005, 81, 87-95,https://doi.org/10.1159/000084897.

52. Adriaens, I.; Jacquet, P.; Cortvrindt, R.; Janssen, K.; Smitz, J. Melatonin has dose- dependent effects on folliculogenesis, oocyte maturation capacity and steroidogenesis. Toxicology 2006, 228, 333-343, https://doi.org/10.1016/j.tox.2006.09.018.

53. Rönnberg, L.; Kauppila, A.; Leppäluoto, J.; Martikainen, H.; Vakkuri, O. Circadian and seasonal variation in human preovulatory follicular fluid melatonin concentration. J. Clin. Endocrinol. Metab. 1990, 71, 493496, https://doi.org/10.1210/jcem-71-2-493.

54. Vijayalaxmi; Thomas Jr, C.R.; Reiter, R.J.; Herman, T.S. Melatonin: from basic research to cancer treatment clinics. J. Clin. Oncol. 2002, 20, 2575-2601, https://doi.org/10.1200/jco.2002.11.004.

55. Martínez-Campa, C.; Gonzalez, A.; Mediavilla, M. D.; Alonso-Gonzalez, C.; Sanchez-Barcelo, E.J.; Cos, S. Melatonin enhances the inhibitory effect of aminoglutethimide on aromatase activity in MCF-7 human breast cancer cells. Breast Cancer Res. Treat. 2005, 94, 249-254, https://doi.org/10.1007/s10549-005-9006-X.

56. Fernández-Ladrón, V.; Aguirre-Gorospe, S.; Lapeña-Calavia, S.; Tarrío- Fernández, O.; MuruzabalTorquemada, J.C. Sarcoma mieloide uterino como manifestacion de leukemia aguda mieloide. Rev. Chil. Obstet. Ginecol.2019, 84, 332-336, http://dx.doi.org/10.4067/S0717-75262019000400332.

57. Luboshitzky, R.; Herer, P.; Shen-Orr, Z. Urinary 6-sulfatoxymelatonin excretion in hyperandrogenic women: the effect of cyproterone acetate-ethinyl estradiol treatment. Exp. Clin. Endocrinol. Diabetes2004, 112, 102-107, https://doi.org/10.1055/s-2004-815765.

58. Carneiro, S.R.; da Silva Lima, A.A.; de Fátima Silva Santos, G.; de Oliveira, C.S.B.; Almeida, M.C.V.; da Pinheiro, M.C.N. Relationship between Oxidative Stress and Physical Activity in Women with Squamous Intraepithelial Lesions in a Cervical Cancer Control Program in the Brazilian Amazon. Oxid. Med. Cell Longev. 2019, 2019, 1-7, https://doi.org/10.1155/2019/8909852.

59. Shafabakhsh, R.; Reiter, R.J.; Mirzaei, H.; Teymoordash, S.N.; Asemi, Z. Melatonin: A new inhibitor agent for cervical cancer treatment. J. Cell Physiol. 2019, 234, 21670-21682,https://doi.org/10.1002/jcp.28865.

60. Lima, N.A.; Santana, N.d.C.S.; de Lima, N.C.A.; Lazarin-Bidóia, D.; Bonfim-Mendonça, P.d.S.; Ueda Nakamura, T.; Nakamura, C.V.; Consolaro, M.E.L.; Ximenes, V.F.; Silva, S.D.O. Antiproliferative effect of apocynin in cervical epithelial cells infected by HPV 16 involves change of ROS production and cell cycle. Med. Chem. Res. 2017, 26, 2853-2860, https://doi.org/10.1007/s00044-017-1984-9.

61. Halliwell, B. Role of free radicals in the neurodegenerative diseases. Drugs Aging 2001, 18, 685-716, https://doi.org/10.2165/00002512-200118090-00004.

62. Woodman, C.B.; Collins, S.I.; Young, L.S. The natural history of cervical HPV infection: unresolved issues. Nat. Rer. Cancer 2007, 7, 11-22, https://doi.org/10.1038/nrc2050.

63. Perry, J.J.P.; Fan, L.; Tainer, J.A. Developing master keys to brain pathology, cancer and aging from the structural biology of proteins controlling reactive oxygen species and DNA repair. Neuroscience 2007, 145, 1280-1299, https://doi.org/10.1016/j.neuroscience.2006.10.045.

64. Johnston, J.R.; Godzik, C.A.; Cohn, Z.A. Increased superoxide anion production by immunologically activated and chemically elicited macrophages. Jpn. J. Exp. Med. 1978, 148, 115-129, https://doi.org/10.1084/jem.148.1.115.

65. Näslund, U.; Häggmark, S.; Johansson, G.; Marklund, S.L.; Reiz, S.; Öberg, A. Superoxide dismutase and catalase reduce infarct size in a porcine myocardial occlusion-reperfusion model. J. Mol. Cell. Cardiol. 1986, 18, 1077-1084, https://doi.org/10.1016/S0022-2828(86)80294-2. 
66. Naidu, M.S.K.; Suryakar, A.N.; Swami, S.C.; Katkam, R.V.; Kumbar, K.M. Oxidative stress and antioxidant status in cervical cancer patients. Indian J. Clin. Biochem. 2007, 22, 140-144, https://doi.org/10.1007/bf02913333.

67. Fridovich, I. Superoxide anion radical $\left(\mathrm{O}_{2}\right)$, superoxide dismutases, and related matters. J. Biol. Chem.1997, 272, 18515-18517, https://doi.org/10.1074/jbc.272.30.18515.

68. Perry, J.J.P.; Shin, D.S.; Getzoff, E.D.; Tainer, J.A. The structural biochemistry of the superoxide dismutases. Biochim. Biophys. Acta Proteins Proteom. 2010, 1804, 245-262, https://doi.org/10.1016/j.bbapap.2009.11.004.

69. Santos, A.F.; Machado, R.R.; Neto, J.M.M.; Menezes, M.G.V.; Silva, G.B.A.; Santos, S.L. The diosmin antioxidant effect: an integrative review. ABCS Health Sciences 2018, 43, 175180,http://doi.org/10.7322/abcshs.v43i3.1024.

70. Katz, D.F. Human cervical mucus: research update. Am. J. Obstet. Gynecol. 1991, 165, 1984-1986, https://doi.org/10.1016/S0002-9378(11)90559-6.

71. Wolf, D.P.; Blasco, L.; Khan, M.A.; Litt, M. Human cervical mucus oral contraceptives and mucus rheologic properties. Fertil. Steril. 1979, 32, 166-169..

72. Critchfield, A.S.; Yao, G.; Jaishankar, A.; Friedlander, R.S.; Lieleg, O.; Doyle, P.S.; Ribbeck, K. Cervical mucus properties stratify risk for preterm birth. PloS ONE 2013, 8, 1-7, https://doi.org/10.1371/journal.pone.0069528.

73. Singangutti, R. Incidence and etiologic factors responsible for anovulation in infertility cases. Int. J. Reprod. Contracept. Obstet. Gynecol. 2018, 7, 1567-1570, http://doi.org/10.18203/2320-1770.ijrcog20181357.

74. Díaz, L.; Ceja-Ochoa, I.; Restrepo-Angulo, I.; Larrea, F.; Avila-Chávez, E.; García-Becerra, R.; AlvarezRios, E. Estrogens and human papilloma virus oncogenes regulate human ether-a-go-go-1 potassium channel expression. Cancer Res.2009, 69, 3300-3307, https://doi.org/10.1158/0008-5472.CAN-08-2036.

75. Maganhin, C.C.; Carbonel, A.A.; Hatty, J.H.; Fuchs, L.F.; Oliveira-Júnior, I.S.; Simões, J.M.; Soares, J.J. Melatonin effects on the female genital system: a brief review. Rev. Assoc. Med. Bras. 2008, 54, 267-271, https://doi.org/10.1590/s0104-42302008000300022.

76. Cos, S.; González, A.; Martínez-Campa, C.; Mediavilla, M.D.; Alonso-González, C.; Sánchez-Barceló, E.J. Estrogen-signaling pathway: a link between breast cancer and melatonin oncostatic actions. Cancer Detec. Prev. 2006, 30, 118-128.

77. Río, B.D.; Pedrero, J.M.G.; Martínez-Campa, C.; Zuazua, P.; Lazo, P.S.; Ramos, S. Melatonin, an endogenous-specific inhibitor of estrogen receptor $\alpha$ via calmodulin. J. Biol. Chem. 2004, 279, 38294-38302, https://doi.org/10.1074/jbc.m403140200.

78. Reiter, R.J.; Mayo, J.C.; Tan, D.-X.; Sainz, R.M.; Alatorre-Jimenez, M.; Qin, L. Melatonin as an antioxidant: under promises but over delivers. J. Pineal. Res. 2016, 61, 253-278, https://doi.org/10.1111/jpi.12360.

79. Karaaslan, C.; Suzen, S. Antioxidant properties of melatonin and its potential action in diseases. Curr. Top. Med. Chem. 2015, 15, 894-903, https://doi.org/10.2174/1568026615666150220120946.

80. Canada, A.T.; Calabrese, E.J. Superoxide dismutase: its role in xenobiotic detoxification. Pharmacol. Ther.1989, 44, 285-295, https://doi.org/10.1016/0163-7258(89)90068-5.

81. Han, L.; Padua, E.; Hart, K.D.; Edelman, A.; Jensen, J.T. Comparing cervical mucus changes in response to an oral progestin or oestrogen with drawal in ovarian-suppressed women: a clinical pilot. Eur. J. Contracep Repr. 2019, 24, 209-215, https://doi.org/10.1080/13625187.2019.1605503. 